\title{
A Study of Accuracy and Time Delay for Bilateral Master-Slave Industrial Robotic Arm Manipulator System
}

\author{
Nuratiqa Natrah Mansor ${ }^{1, *}$, Muhammad Herman Jamaluddin ${ }^{2}$, Ahmad Zaki Shukor ${ }^{3}$ and Chee Cong Lok \\ ${ }_{1,2,3,4}$ Centre for Robotics and Industrial Automation (CERIA), Faculty of Electrical Engineering, Universiti Teknikal Malaysia \\ Melaka, Malaysia
}

\begin{abstract}
Bilateral master-slave industrial robotic arm manipulator system is an advanced technology used to help human to interact with environments that are unreachable to human, due to its remoteness or perilous. The system has been used in different areas such as tele-surgery, autonomous tele-operation for sea and space operation and handling explosive or high radiation operation fields. It is beneficial both for science and society. Remarkably, the system is not common and generally used in Malaysia. Likewise, the number of research conducted that focused about this technology in our country manufacturing industry are not yet discovered and existent. The implementation of this bilateral manipulator system in an industrial robot could be useful for industrial imminent and development over our country and people, specifically for production yield size and human operative. Hence, the study of bilateral robotic arm manipulator system in an industrial robot and analyzation of its performance and time delay in 3 differ controllers will be discussed to attest the efficiency and its effectiveness on the said design system. The experiment conducted was on KUKA youBot arm in V-Rep simulation with three different controllers (P, $\mathrm{PD}, \mathrm{PID})$.
\end{abstract}

\section{Introduction}

In robotic technology, haptic system is known to be a medium that can give force sensation to user from real environment. Basically, haptics system can be in synchronous and asynchronous multilateral control for walking motion [1]. Haptic information can also be transmitted into two directions which is unilateral and bilateral. Unilateral is a transmission of information in one direction only without giving feedback whereas bilateral direction is transmission of information that consist of action and reaction from environment contact [2]. While, bilateral master-slave telerobotic is a potential useful tool to substitute human for carry out difficult or unreachable load and task. Position or velocity and force information are bidirectionally transmitted in this type of control system. These physical variables are controlled locally [3]. The efficiency of the master-slave robot in term of synchronization of position between master and slave arm and time delay is rest on the accuracy from the tasks. In the complexity of communication network between computer and masterslave telerobotic system, time-delay is unavoidable during the data packet exchanged. This is because the subsystems, which is master and slave robot may have located far from each other [4]. The delay give rise to latency and interference in terms of the system performance during transmitting the tactile sensation to other pair of its subsystem. It deteriorates overall performances and thereby may destabilize the system works [5]. In this century, this kind of telerobotic arms have become an emerging technology in this century and has many potential applications in numerous research fields and works including robotic rehabilitation [6]. The main redundancy of this technology is that it helps human to interact with environments that are not accessible and also risky. There are five basic parts involved in master-slave telerobotic system which include human operator, master robot, slave robot, communication channel and the environment.

Therefore, the motivation of this research is to develop a bilateral master-slave telerobotic arm manipulator system by simulation work of V-Rep and Python (x, y) software. Besides, the project also proposed to analyse the time-delay and the performance of robotic arm system in term of accuracy as well as its efficiency when different type's controllers are applied and tested on the control system.

\section{Research methodology}

In this section, there are three steps that will be implemented and discussed to develop the proposed system. In order to achieve the listed objectives as stated in previous introduction, every following course of procedure have been conducted step by step in this project. To visualize the research flow, every major step of the research is presented briefly in flow chart below as in Fig. 1.

\footnotetext{
*Corresponding author:m011620002@student.utem.edu.my
} 


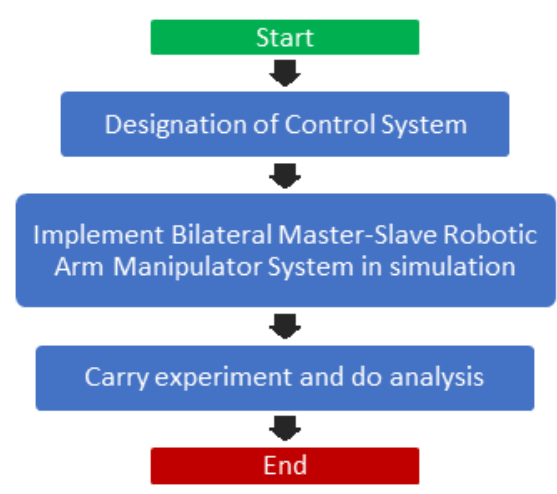

Fig. 1. Flow Chart of the Research

\subsection{Designation of control system}

A reliable and ideal design of control system is utmost important for a precise motion control. In bilateral control, the accuracy of motion between master and slave robot is emphasized, hence a good control system is necessary in this project. To make it clear, several types of controller in control systems have been tested for verification, comparison and analysation of respective performances. It is for selecting the controller which has the best performance for an ideal bilateral master-slave manipulator system. Eventually, there are 3 types of control system which are P control, PD control and PID control. A block diagram of a single link motor control system without any controller is indicated as in Fig. 2. After that, $\mathrm{P}$ controller which carry an important variable is added as shown in Fig. 3.

$\mathrm{P}$ control also known as proportional term, $K_{p}$. The input of $K_{p}$ is the difference between input angle and output angle of the system. $K_{p}$ is used to reduce the rise time of the system which give system a quick respond and reduce the steady state error. The shorter the rise time and settling time, the better the performance of a system. Therefore, the system is more stable when overshoot is smaller. $K_{p}$ purpose in a control system is for achieving desired response of critical damping. This controller also is much simple in tuning the gain.

Afterwards, a derivative term known as $K_{d}$ is added into the P control system as shown in Fig. 4 to become second design of control system which is PD control system. In PD control system, $K_{d}$ is multiplied by difference between the rate of change of output angle and the rate of change of input angle. $K_{d}$ is used to help reducing the settling time, eliminate the overshoot problem and improve the stability of the system.

The third design control system is further improved with adding another term which is integral term, $K_{i}$ into the current PD control system. This results in forming a new design of control system as shown in Fig. 5. $K_{i}$ is used to reduce and eliminate steady- state error. At most cases, there are some small error exists due to the external disturbance from environment although $K_{i}$ able to lead the system into zero steady-state error, which is an ideal situation for a built control system.

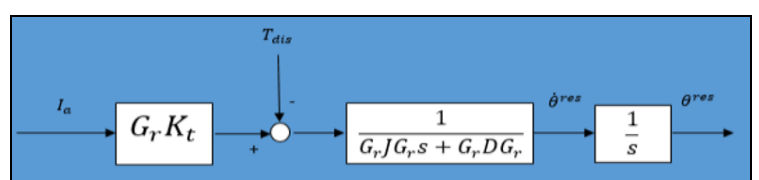

Fig. 2. Block diagram of motor

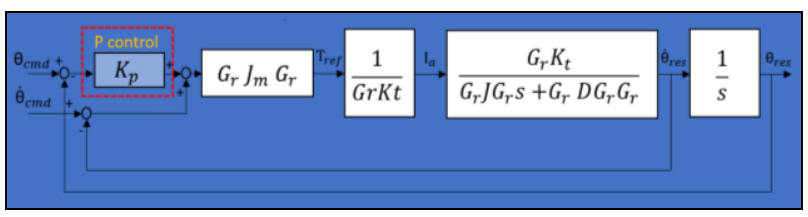

Fig. 3. Block diagram adding $P$ control to the manipulator system

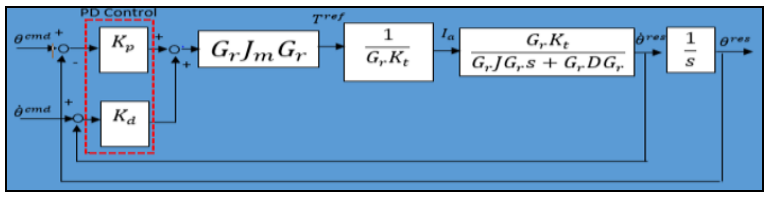

Fig. 4. Block diagram adding PD control to the manipulator system

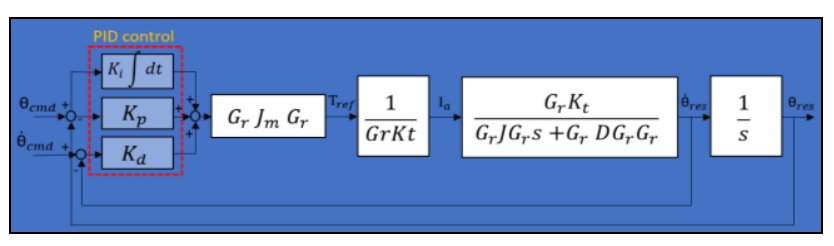

Fig. 5. Block diagram adding PID control to the manipulator system

where;

$\theta_{\text {res }}[\mathrm{rad}]:$ Respond angle of motor rotation

$\theta_{c m d}[\mathrm{rad}]:$ Command angle of motor rotation

$I_{a}[\mathrm{~A}]$ : Torque electric current

$T_{\text {dis }} / T_{\text {ref }}[\mathrm{Nm}]$ : Motor torque

$G_{r}$ : Gear ratio

$K_{t}[\mathrm{Nm} / \mathrm{A}]$ : Torque constant

$J_{m}\left[\mathrm{kgm}^{2}\right]$ : Inertia of the motor shaft

$D[\mathrm{Nmrad} / \mathrm{s}]$ : Viscous friction factor

$K_{p}$ : Proportional gain in $\mathrm{P}$ controller

$K_{d}$ : Proportional gain in PD controller

$K_{i}$ : Proportional gain in PID controller

\subsection{Implementation of bilateral master-slave telerobotic arm manipulator system in simulation}

To verify the designed control systems, a simulation need to be done to prove the designed control system is robust. In this project, V-Rep and Python (x, y) are used. V-Rep is used due to it already has the built in KUKA youBot and much easier to design the scene and object properties while python is used for programming language as it has more functions and easy to be connected with V-Rep through remote API address for communication channel.

When simulation starts, external arm will swing and exerted force on master youBot. Expectedly, slave robot will track the movement of master robot accurately. An obstacle is placed on the slave robot to block it from 
moving while rotating. At the same time, master robot arm will also stop at the same position even though there is no obstacle comes in contact with the master of youBot arm. This situation can be referred in Fig. 6 .

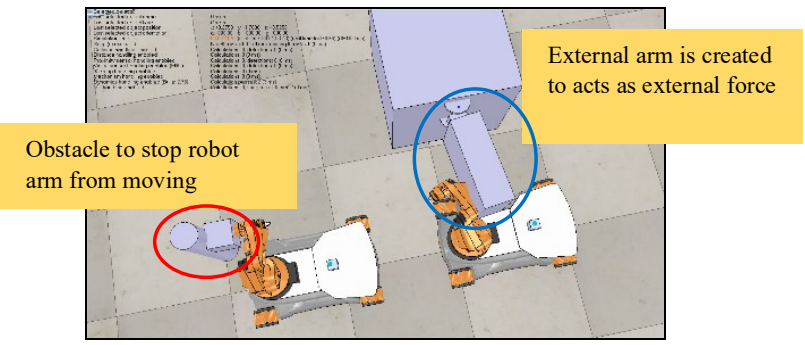

Fig. 6. Simulation of two bilateral master-slave KUKA youBot (master on the right and slave on the left)

In bilateral concept, every command signal applied on the operator at master manipulator can be executed by the end effector at slave manipulator [7]. Moreover, operator can measure the stiffness of executing subject or object at the end-effector of slave manipulator. To visualize the result, the angle of the master youBot arm and slave youBot arm are extracted and plotted in graph. The experiments have been carried out 6 times with different values of $K_{p}, K_{i}$ and $K_{d}$ respectively. The accuracy of movement between the master and slave robot, time delay of the movement between the master and slave robot and precision of final angle to the reference angle could be calculated by using the formula in Equation 1, 2 and 3.

$$
\text { Accuracy }=\left[1-\frac{\left(y_{m}-x_{m}\right)-\left(y_{s}-x_{s}\right)}{\left(y_{m}-x_{m}\right)}\right] \times 100 \%
$$

where;

$x_{m}=$ Initial position for master robot

$x_{s}=$ Final position for slave robot

$y_{m}=$ Initial position for master robot

$y_{s}=$ Final position for slave robot

$$
\text { Time delay }=\left(t_{f m}-t_{i m}\right)-\left(t_{f s}-t_{i s}\right)
$$

where;

$t_{i m}=$ Initial time taken for master robot

$t_{i s}=$ Initial time taken for slave robot

$t_{f m}=$ Final time taken for master robot

$t_{f s}=$ Final time taken for slave robot

$$
\text { Precision }=\left[1-\frac{\left(\theta_{\text {ref }}-\theta_{f}\right)}{\theta_{\text {ref }}}\right] \times 100 \%
$$

where;

$\theta_{\text {ref }}=$ Reference angle of the robot

$\theta_{f}=$ Final angle of the robot

To transfer the information in haptic communication between the bilateral telerobotic system, position tracking and law of action and reaction between master and slave system are necessary. Based on the block diagram in Fig. 7, the control system are similar as the previous PID control system as in Fig. 5 but, the changed is there are two similar block diagram applied regard to robotic arm system (master and slave). From the block diagram, $T_{m}$ represent the torque of master manipulator provided by human operator or external force while $T_{s}$ represents the torque of slave manipulator applied by environment. General equation of bilateral master-slave telerobotic system is as shown in equation 4.

$$
\ddot{\theta}=K_{p}\left(\theta^{c m d}-\theta^{n s}\right)+K_{d}\left(\dot{\theta}^{c m d}-\dot{\theta}^{n s}\right)
$$

From the general equation, the equation of motion in master and slave system are in equation 5 and 6 correspondingly.

$$
\begin{aligned}
& \ddot{\theta} m=K_{p}(s-\theta m)+K_{d}(\dot{\theta} s-\dot{\theta} m) \\
& \ddot{\theta} s=K_{p}(\theta m-\theta s)+K_{d}(\dot{\theta} m-\dot{\theta} s)
\end{aligned}
$$

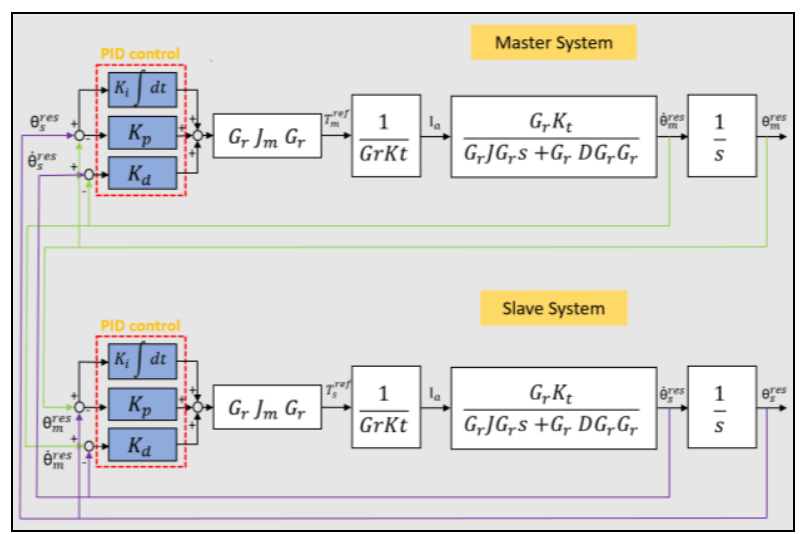

Fig. 7. Block Diagram of bilateral telerobotic arm manipulator

\section{Result and Discussion}

To prove the common mode and differential mode of bilateral master-slave telerobotic arm manipulator system, two separate experiment has been conducted. In common mode, the summation of external torque from master and slave system must always be zero. Hence, for this part, different maximum torque of KUKA youBot Joint 1 (lower part of the arm robot as shown in Fig. 8) is set to show different results in order to prove the common mode is achieved.

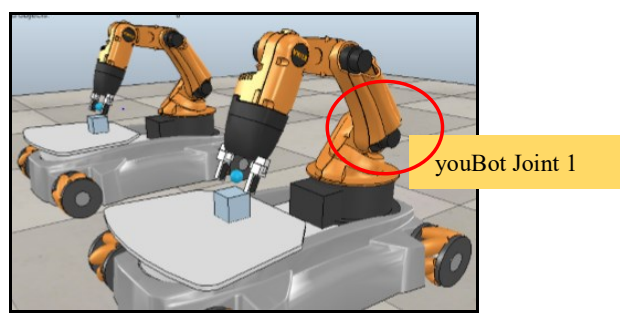

Fig. 8. Joint 1 of KUKA youBot

Meanwhile, the maximum torque of created external arm is adjusted to a suitable torque that will makes the robot to exert its maximum torque while in the same time the master robot arm would not be moved when slave youBot is being blocked. This is because when the torque of extra arm is too large and move the master robot arm, the master robot arm unable to reach its maximum torque when the robot is moving and hence, did not give the desired and expected result. $K_{p}$ is set to 
1. After the simulation starts, the external arm will swing its arm and hit master KUKA youBot arm and accordingly, slave youBot arm will following the motion of master until it is being blocked. This will cause slave youBot arm having maximum reaction force against the obstacle. After the slave is being blocked by the corresponding obstacle, the master will also follow the motion from the slave. This experiment is repeated for three times with different maximum torque of external arm and KUKA youBot joint 1 arm as shown in Table 1.
Forces reading for both arms are recorded and plotted as shown in graphs in Table 2.

Table 1. Maximum torque of external arm and KUKA youBot arm.

\begin{tabular}{|c|c|}
\hline $\begin{array}{c}\text { External arm maximum } \\
\text { torque (Nm) }\end{array}$ & $\begin{array}{c}\text { youBot maximum torque } \\
\text { (Nm) }\end{array}$ \\
\hline 10 & 5 \\
\hline 35 & 15 \\
\hline 55 & 25 \\
\hline
\end{tabular}

Table 2. Graph of forces for master and slave arm for common mode

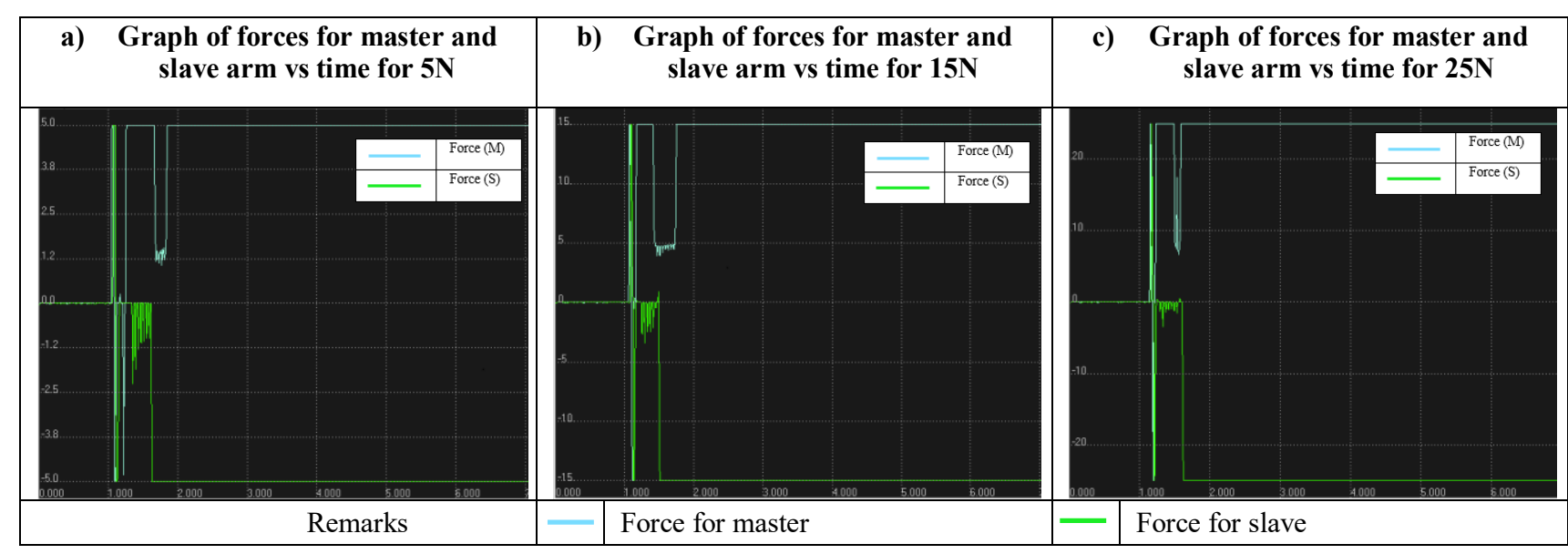

Referring to figure a) in Table 2, it shows that time before $1.5 \mathrm{~s}$, the force of slave youBot arm is zero, this is because the slave arm is in free contact form any obstacle. However, once it is being blocked by an obstacle, it immediately has a reaction force against the obstacle. The graph shows that master youBot arm has giving its maximum torque of $5 \mathrm{~N}$ while slave youBot arm has giving its maximum torque of $-5 \mathrm{~N}$ in the experiment. This proved that this bilateral master-slave telerobotic manipulator arm system has achieved the common mode and obey the equation which state that the summation of external torque from master and slave system must always be zero. To prove the validity of the result, experiment is repeated with different maximum torque set to both master and slave youBot arm and the result is shown as in figure b) and c) in Table 2. The results are almost same between these 3 figures, but differ in force values and responded force pattern. In short, the first requirement on designing bilateral system is success.
In differential mode, the subtraction of position between the master youBot arm and slave youBot arm is emphasised. In this experiment, the fixed variable will be maximum torque of KUKA youBot arm, which will fix the maximum torque youBot arm to $5 \mathrm{Nm}$ and the external arm to $35 \mathrm{Nm}$ and the manipulated variable will be the parameter value of $K_{p}, K_{d}$ and $K_{i}$. In expected result, slave youBot should follow the motion of master youBot after the simulation is started.

Table 3. Parameter value of $K_{p}, K_{d}$ and $K_{i}$

\begin{tabular}{|c|c|c|}
\hline Value of $\boldsymbol{K}_{\boldsymbol{p}}$ & Value of $\boldsymbol{K}_{\boldsymbol{i}}$ & Value of $\boldsymbol{K}_{\boldsymbol{d}}$ \\
\hline 1 & 0.80 & 0.0100 \\
\hline 5 & 0.10 & 0.0010 \\
\hline 8 & 0.50 & 0.0050 \\
\hline 10 & 0.20 & 0.0005 \\
\hline 20 & 1.60 & 0.0050 \\
\hline 50 & 4.65 & 0.0500 \\
\hline
\end{tabular}

Table 4. Graph of Force and Angle of master and slave arm for each controller for differential mode between different controllers

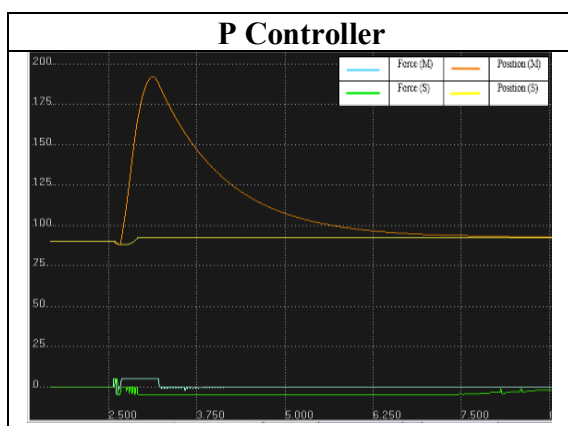

a) $K_{p}=1$

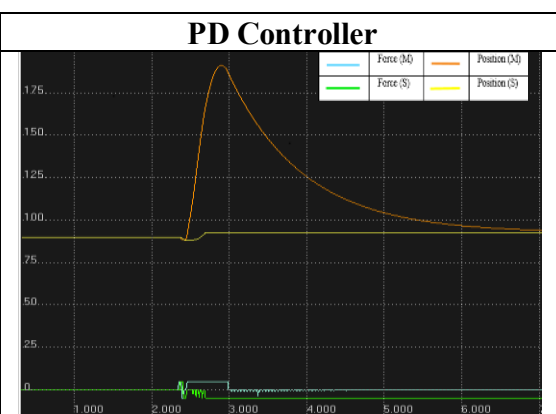

b) $\mathrm{K}_{\mathrm{p}}=1, \mathrm{~K}_{\mathrm{d}}=0.80$

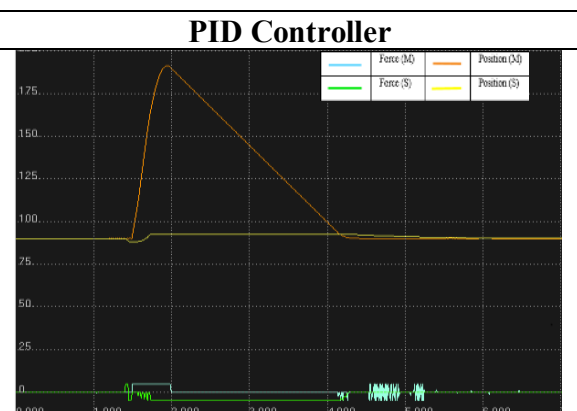

c) $\mathrm{K}_{\mathrm{p}}=1, \mathrm{~K}_{\mathrm{d}}=0.80, \mathrm{~K}_{\mathrm{i}}=0.0100$ 


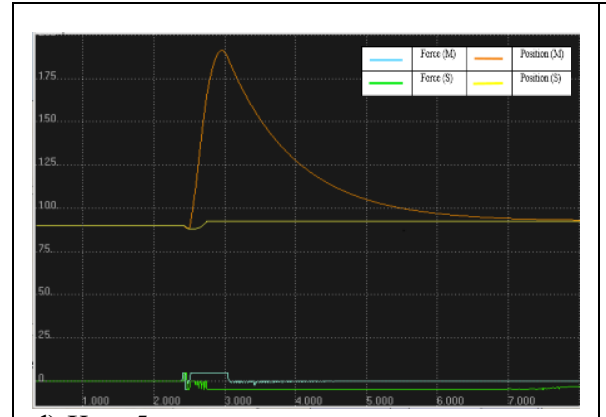

d) $K_{p}=5$

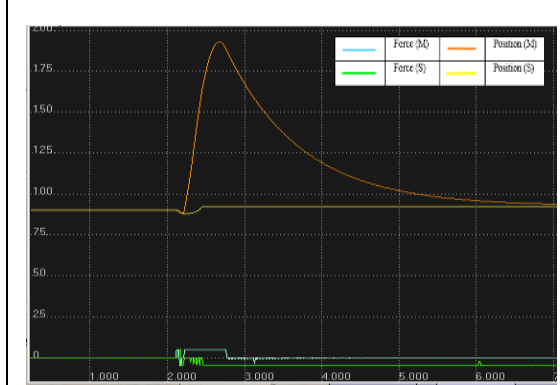

g) $K_{p}=8$

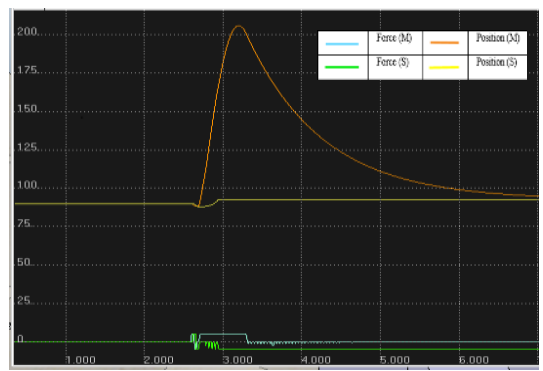

j) $\mathrm{K}_{\mathrm{p}}=10$

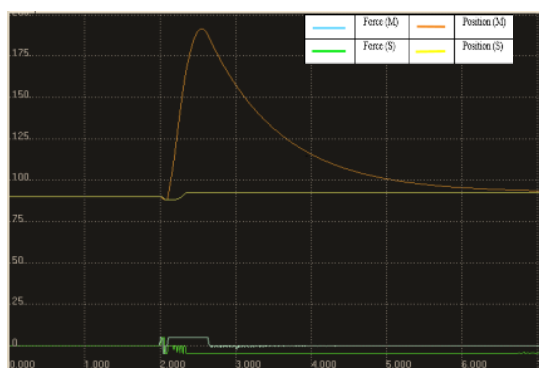

m) $\mathrm{K}_{\mathrm{p}}=20$

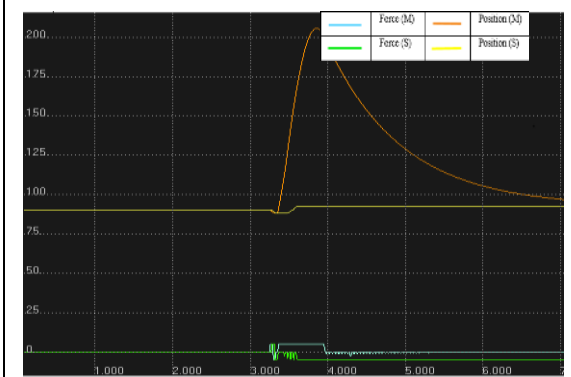

p) $K_{p}=50$

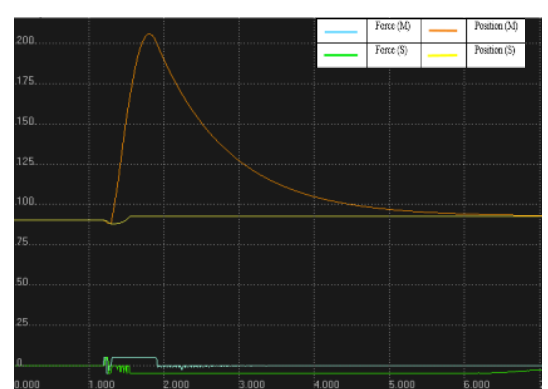

e) $K_{p}=5, K_{d}=0.10$

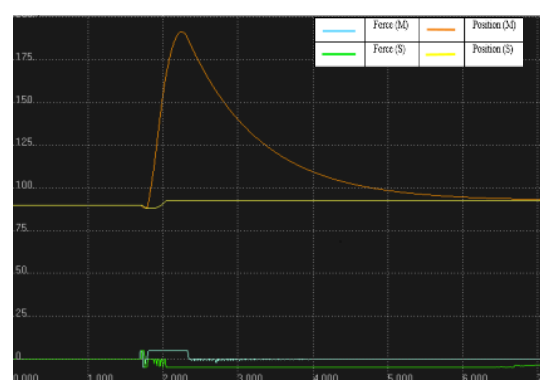

h) $\mathrm{K}_{\mathrm{p}}=8, \mathrm{~K}_{\mathrm{d}}=0.50$

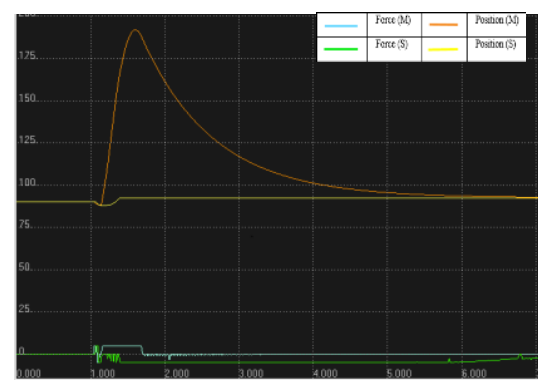

k) $K_{p}=10, K_{d}=0.20$

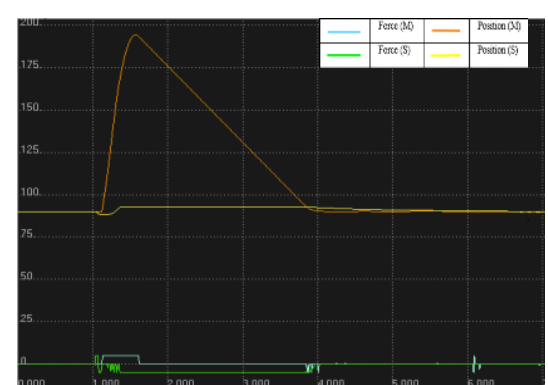

n) $K_{p}=20, K_{d}=1.60$

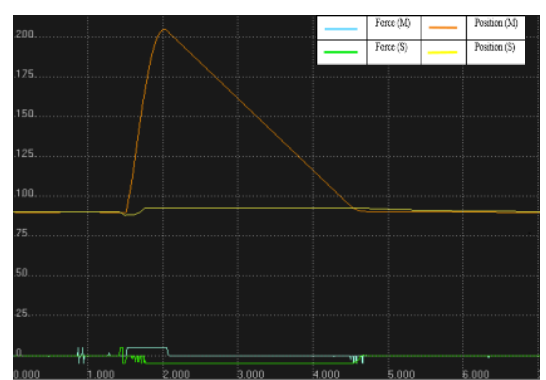

q) $K_{p}=50, K_{d}=4.65$

Force for master

Force for slave

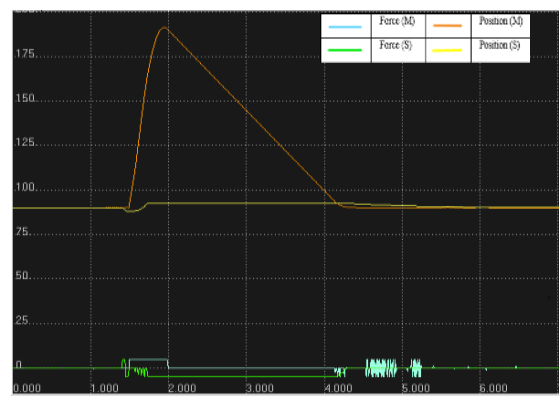

f) $K_{p}=5, K_{d}=0.10, K_{i}=0.0010$

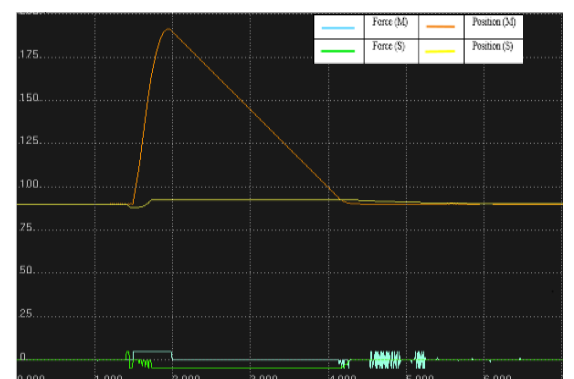

i) $\mathrm{K}_{\mathrm{p}}=8, \mathrm{~K}_{\mathrm{d}}=0.50, \mathrm{~K}_{\mathrm{i}}=0.0050$

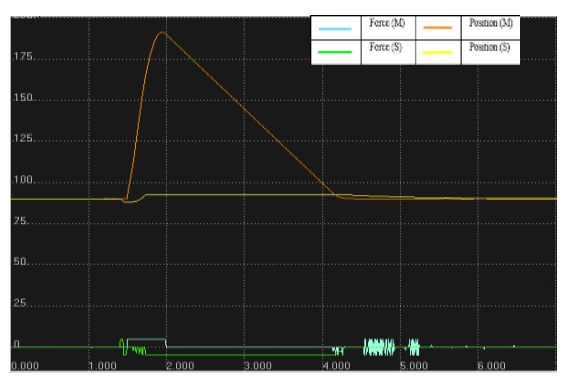

1) $\mathrm{K}_{\mathrm{p}}=10, \mathrm{~K}_{\mathrm{d}}=0.20, \mathrm{~K}_{\mathrm{i}}=0.0005$

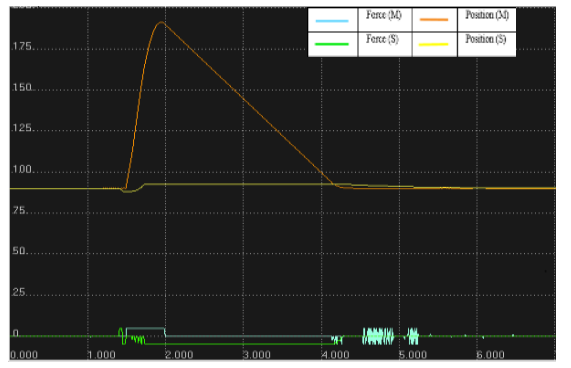

o) $\mathrm{K}_{\mathrm{p}}=20, \mathrm{~K}_{\mathrm{d}}=1.60, \mathrm{~K}_{\mathrm{i}}=0.0050$

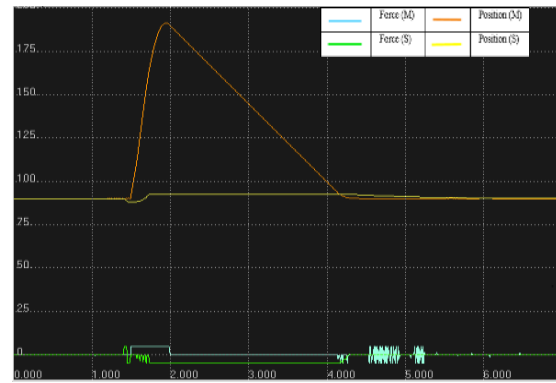

r) $\mathrm{K}_{\mathrm{p}}=50, \mathrm{~K}_{\mathrm{d}}=4.65, \mathrm{~K}_{\mathrm{i}}=0.0500$

Remarks

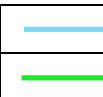

Position for master

Position for slave 
Table 5. Accuracy result for $P$ control system

\begin{tabular}{|c|c|c|c|}
\hline Kp & Accuracy (\%) & Time-delay (s) & Precision (\%) \\
\hline 1 & 99.44 & 0.5344 & 99.45 \\
\hline 5 & 99.75 & 0.2273 & 99.24 \\
\hline 8 & 99.74 & 0.2130 & 99.35 \\
\hline 10 & 99.62 & 0.2050 & 97.85 \\
\hline 20 & 94.11 & 0.1855 & 96.68 \\
\hline 50 & 55.77 & 0.1767 & 94.54 \\
\hline
\end{tabular}

Table 6. Accuracy result for PD control system

\begin{tabular}{|c|c|c|c|c|}
\hline Kp & Kd & Accuracy (\%) & $\begin{array}{c}\text { Time-delay } \\
\text { (s) }\end{array}$ & $\begin{array}{c}\text { Precision } \\
\text { (\%) }\end{array}$ \\
\hline 1 & 0.80 & 98.06 & 0.1909 & 98.12 \\
\hline 5 & 0.10 & 99.92 & 0.2075 & 99.85 \\
\hline 8 & 0.50 & 99.24 & 0.1850 & 99.53 \\
\hline 10 & 0.20 & 99.99 & 0.1866 & 99.24 \\
\hline 20 & 1.60 & 97.85 & 0.1699 & 99.98 \\
\hline 50 & 4.65 & 86.41 & 0.1780 & 99.98 \\
\hline
\end{tabular}

Table 7. Accuracy result for PID control system

\begin{tabular}{|c|c|c|c|c|c|}
\hline $\mathbf{K p}$ & $\mathbf{K d}$ & $\mathbf{K i}$ & $\begin{array}{c}\text { Accuracy } \\
\mathbf{( \% )}\end{array}$ & $\begin{array}{c}\text { Time- } \\
\text { delay (s) }\end{array}$ & $\begin{array}{c}\text { Precision } \\
\mathbf{( \% )}\end{array}$ \\
\hline 1 & 0.80 & 0.0100 & 97.13 & 0.1921 & 99.92 \\
\hline 5 & 0.10 & 0.0010 & 99.63 & 0.2072 & 99.98 \\
\hline 8 & 0.50 & 0.0050 & 97.81 & 0.1876 & 99.99 \\
\hline 10 & 0.20 & 0.0005 & 99.89 & 0.1873 & 99.99 \\
\hline 20 & 1.60 & 0.0050 & 99.18 & 0.1690 & 99.97 \\
\hline 50 & 4.65 & 0.0500 & 87.52 & 0.2380 & 99.92 \\
\hline
\end{tabular}

According to the six-plotted graph in figure a), d), g), $\mathrm{j}), \mathrm{m})$ and $\mathrm{p}$ ) in Table 4 when the system used $P$ controller, the angle of master and slave youBot will reach almost same final angle exceptional for Figure $p$ ). This means that the system achieved the differential mode which obey the equation of subtraction of position from master and slave must be zero. The system also reached its steady state without fluctuated. Accuracy and time-delay between master and slave arm are calculated using Equation (1) and (2) as stated in Section 3. The result is plotted in Table 5. By referring to Table 5, the most accurate for system performance is when $K_{p}=5$, whereby it reached $99.7526 \%$ while the least accurate system is when value of $K_{p}$ is 50 which merely $55.7752 \%$.

Eventhough it is least accurate, the delay is the shortest which is only $0.1767 \mathrm{~s}$ while $K_{p}=1$ results $0.5344 \mathrm{~s}$, making it the longest delay. Therefore, it can say that the bigger the value of $K_{p}$, the lowest the value for time-delay. Thus, for $\mathrm{P}$ controller, the most suitable proportional value is when $K_{p}=5$ as it obeys both common and differential mode, has critical damping, near to zero steady state error, high accuracy and short time-delay between both bilateral manipulator arms.

For PD Controller, based on the six-plotted graph in figure b), e), h), k), n) and q) in Table 4 when the system used PD controller, the angle of master and slave youBot will reach almost same final angle. This means that the system achieved the differential mode which obey the equation of subtraction of position from master and slave must be zero. The system also stable and reached its steady state without fluctuated. By referring to Table 5 , The highest accuracy of system is when $K_{p}=10$, and $K_{d}=0.2$ whereby $99.9996 \%$ and shortest in terms of timedelay with $0.1699 \mathrm{~s}$. However, the least accurate system is when $K_{p}=50$ and $K_{d}=4.65$. The accuracy is just $86.4099 \%$ which improves about $30 \%$ of the performance comparing when the system use $\mathrm{P}$ controller. In short, by using PD controller, the most suitable proportional and derivative value is when $K_{p}=10$ and $K_{d}=0.2$ as it obeys both common and differential mode, has critical damping, zero steady state error, high accuracy and acceptable time-delay between both bilateral manipulator arms.

On the same time, PID controller also responded that it achieved differential mode and obey the equation whereby the subtraction for each position resulting to zero. Based on Figure c), f), i), 1), o) and r), each system reaches slight steady state from the reference angle. From the observation, there are three system that has reached over $99 \%$ but the system with $K_{p}=10, K_{d}=0.2$, $K_{i}=0.05$ has outperformed others by reaching $99.8894 \%$. Whereas, the shortest time delay in the system is when $K_{p}=20, K_{d}=1.6, K_{i}=0.005$ when it responded in just $0.169 \mathrm{~s}$. Hence, the most suitable value for proportional, derivative and integral term are $K_{p}=10, K_{d}=0.2$, and $K_{i}=0.0005$. This is because the system achieved differential mode, has least steady state error, high accuracy and acceptable time-delay.

\section{Conclusion and Recommendations}

In a nutshell, all objectives have been achieved in this project. From the findings of results, the performance and feedback of said system in differential mode is proven. The suggested bilateral master-slave control system has been proved by carrying experiments with certain set of variables. Responded data, which are force and also angle (position) of the bilateral control system are used for plotting graphs on the system response. As the basic requirement for common mode and differential mode has been validated, the development of bilateral master-slave telerobotic arm manipulator system is realized and successfully proven.

Overall, by carrying out experiments by using different value from different kind of controllers $\left(K_{p}, K_{i}\right.$ and $K_{d}$ ), most of the system achieved very high accuracy between master and slave youBot arm simulation which is over than $95 \%$. The time delay is also short whereby around $0.2 \mathrm{~s}$. However, the precision of youBot rotated angle to the reference angle and the settling time has showed in huge difference with different control system and different value of proportional term, $K_{p}$, derivative term, $K_{d}$, and integral term $K_{i}$. It can be concluded that most suitable controllers are when using $K_{p}=5$ for $\mathrm{P}$ controller, the PD controller with $K_{p}=10$ and $K_{d}=0.2$ for the most precise control with zero steady state error, or PID controller with $K_{p}=10, K_{d}=0.2$, and $K_{i}=0.0005$ with little steady-state error but with shorter settling time which is $1 \mathrm{~s}$.

For future research, the system designed is expected to be carried out with the real KUKA youBot so that the 
differences between real time and simulation performances can be observed, analysed and understand.

Furthermore, future works can be developed by integrated the manipulator system by other control system such as disturbance observer (DOB) and reaction force observer (RFOB) as these two well-known controllers are potentially to gain the efficiency and smooth feedback for precise control system.

We wish to express our gratitude to Universiti Teknikal Malaysia Melaka (UTeM) especially for Robotics and Industrial Automation (RIA) research group in the Centre of Excellence in Robotis and Industrial Automation (CeRIA), Centre of Research and Innovation Management (CRIM) and to the Faculty of Electrical Engineering from UTeM by giving us financial (University Short Term Research Grant) support as well as moral support for completing this project successfully.

\section{References}

1. Muis and K. Ohnishi, "Cooperative Mobile Manipulator with Dual Compliance Controllers based on Estimated Torque and Visual Force," 2006 IEEE International Conference on Mechatronics, Budapest, pp. 619-624 (2006)

2. L. J. Wei, A.Z. Hj. Shukor, M.H. Jamaluddin, "Investigation on Force Scaling for Multi Degree of
Freedom Bilateral Teleoperation Control System," IJMME, vol.16, no. 16, pp. 1-11 (2016)

3. H. Morimitsu, S. Katsura and K. Ohnishi, "Performance enhancement of bilateral control under time delay using nonlinear filter," 2014 IEEE 13th International Workshop AMC, Yokohama, pp. 735740 (2014)

4. S. Nishimura and S. Katsura, "Multilateral control under time delay for decoupling force and velocity controllers," 2016 IEEE 25th ISIE, Santa Clara, CA, pp. 1258-1263 (2016)

5. K. Cetin, A. Bayrak and E. Tatlicioglu, "Online time delay estimation in networked control systems with application to bilateral teleoperation," 2016 ECC, Aalborg, pp. 1007-1012 (2016)

6. C. Morito et al., "Development of a haptic bilateral interface for arm self-rehabilitation," 2013 IEEE/ASME International Conference AIM, Wollongong, NSW, pp. 804-809 (2013)

7. M. H. Jamaluddin, T. Shimono and N. Motoi, "Motion navigation in haptic bilateral system based on vision-based force compliance controller taking object coordinate into account," 2014 IEEE 23rd ISIE, Istanbul, pp. 2238-2243 (2014) 